EGU21-12205

https://doi.org/10.5194/egusphere-egu21-12205

EGU General Assembly 2021

(c) Author(s) 2022. This work is distributed under

the Creative Commons Attribution 4.0 License.

\title{
Using the 3D MOCAGE CTM to simulate the chemistry of halogens in the volcanic plume of Etna's eruption in December 2018 at the regional scale
}

\author{
Herizo Narivelo ${ }^{1}$, Virginie Marécal ${ }^{1}$, Paul David Hamer ${ }^{2}$, Luke Surl ${ }^{3,4}$, Tjarda Roberts ${ }^{3,4}$, Mickaël \\ Bacles $^{1}$, Simon Warnach ${ }^{5}$, and Thomas Wagner ${ }^{5}$ \\ ${ }^{1}$ Centre National de Recherches Météorologiques (CNRM), Toulouse, France \\ ${ }^{2}$ Norsk institutt for luftforskning (NILU), Kjeller, Norway \\ ${ }^{3}$ Laboratoire de Physique et Chimie de l'Environnement et de l'Espace (LPC2E), Orléans, France \\ ${ }^{4}$ Laboratoire Atmosphères, Milieux, Observations Spatiales (LATMOS), Paris, France \\ ${ }^{5}$ Max-Planck-Institut für Chemie (MPI-C), Mainz, Germany
}

Volcanoes emit different gaseous species, $\mathrm{SO}$ and in particular halogen species especially bromine and chlorine compounds. In general, halogens play an important role in the atmosphere by contributing to ozone depletion in the stratosphere (WMO Ozone assessment, 2018) and by modifying air composition and oxidizing capacity in the troposphere (Von Glasow et al. 2004). The halogen species emitted by volcanoes are halides. The chemical processing occurring within the plume leads to the formation of $\mathrm{BrO}$ from $\mathrm{HBr}$ following the 'bromine explosion' mechanism as evidenced from both observations and modelling (e.g., Bobrowski et al. Nature, 2003; Roberts et al., Chem. Geol. 2009). Oxidized forms of chlorine and bromine are modelled to be formed within the plume due to the heterogenous reaction of $\mathrm{HOBr}$ with $\mathrm{HCl}$ and $\mathrm{HBr}$, forming $\mathrm{BrCl}$ and $\mathrm{Br} \mathrm{C}$ that photolyses and produces $\mathrm{Br}$ and $\mathrm{Cl}$ radicals. So far, modelling studies were mainly focused on the very local scale and processes occurring within a few hours after eruption.

In this study, the objective is to go a step further by analyzing the impact at the regional scale over the Mediterranean basin of a Mt Etna eruption event. For this, we use the MOCAGE model (Guth et al., GMD, 2016), a chemistry transport model run with a resolution of $0.2^{\circ} \times 0.2^{\circ}$, to quantify the impacts of the halogens species emitted by the volcano on the tropospheric composition. We have selected here the case of the eruption of Mount Etna around Christmas 2018 characterised by large amounts of emissions over several days (Calvari et al., remote sensing 2020; Corrdadini et al., remote sensing 2020). The results show that MOCAGE represents rather well the chemistry of the halogens in the volcanic plume because it established theory of plume chemistry. The bromine explosion process takes place on the first day of the eruption and even more strongly the day after, with a rapid increase of the in-plume $\mathrm{BrO}$ concentrations and a corresponding strong reduction of ozone and NO2 concentrations.

We also compared MOCAGE results with the WRF-CHEM model simulations for the same case study. We note that the tropospheric column of $\mathrm{BrO}$ and $\mathrm{SO}$ in the two models have the same 
order of magnitude with more rapid bromine explosion occurring in WRF-CHEM simulations. Finally, we compared the MOCAGE results to tropospheric columns of $\mathrm{BrO}$ and $\mathrm{SO}_{2}$ retrieved from TROPOMI spaceborne instrument. 